\title{
Novel Thermally-Accessible Structural Distortion and Lattice Strain of a Chiral Cyanide-Bridged Cu (II)-Ni (II) Complex
}

\author{
Takashiro Akitsu* Yuki Endo Yusuke Kimoto and Mao Ohwa
}

Department of Chemistry, Faculty of Science, Tokyo University of Science, 1-3 Kagurazaka, Shinjuku-ku, Tokyo 162-8601, Japan

\begin{abstract}
We have investigated temperature dependence of crystal structure of a chiral cyanide-bridged bimetallic assembly of $\left[\mathrm{CuL}_{2}\right]\left[\mathrm{Ni}(\mathrm{CN})_{4}\right] \cdot 2 \mathrm{H}_{2} \mathrm{O}(\mathbf{1})(\mathrm{L}=(1 R, 2 R)$-diaminocyclohexane). Cell parameters and most of bond distances decreased on cooling for $\mathbf{1}$. However, only a long $\mathrm{Cu}-\mathrm{N}$ bond of semi-coordination increases on cooling, which is the first example of negative thermal elongation of specific bond distances.
\end{abstract}

Keywords: lattice distortion, Jahn-Teller effect, copper, cyanide, temperature.

\section{INTRODUCTION}

Commonly most crystalline materials expand on heating, which is called positive thermal expansion (PTE). However some materials exhibit opposite behavior so-called negative thermal expansion (NTE), which is (anisotropic) expanding of crystal lattice on cooling [1]. The mechanism of NTE is different from materials; for example, releasing guest water molecules from host cyanide-bridged metal-organic frameworks (MOF) [2], coordination polymers showing vibration of bonds, geometrical flexibility due to $\mathrm{d}^{10}-\mathrm{d}^{10}$ metallophillic interactions in cyanide-bridged MOF [3-5], and appropriate crystal arrangement and molecular shapes of organic crystalline materials [6].

Previously, we reported a chiral cyanide-bridged coordination polymer, $\left[\mathrm{CuL}_{2}\right]\left[\mathrm{Ni}(\mathrm{CN})_{4}\right] \cdot 2 \mathrm{H}_{2} \mathrm{O}(\mathbf{1})(\mathrm{L}=(1 R, 2 R)-$ diaminocyclohexane) [7]. As shown in Fig. (1), the crystal packing of 1 exhibits a zigzag one-dimensional chain structure along the crystallographic $b$-axis. Interestingly, one of the two axial semi-coordination $\mathrm{Cu} 1-\mathrm{N} 3^{\mathrm{i}}$ [(i) (-x, y-1/2, -z)] bonds of six-coordinated $\mathrm{Cu}$ environment of $\mathbf{1}$ was extremely long more than $3 \AA$, which was attributed to pseudo JahnTeller elongation and electrostatic interaction mainly. Since the larger $\mathrm{d}^{8}$ ions exhibit the among the isomorphous $\left[\mathrm{CuL}_{2}\right]\left[\mathrm{Pd}(\mathrm{CN})_{4}\right] \cdot 2 \mathrm{H}_{2} \mathrm{O}[8]$ and $\left[\mathrm{CuL}_{2}\right]\left[\mathrm{Pt}(\mathrm{CN})_{4}\right] \cdot 2 \mathrm{H}_{2} \mathrm{O}$ [9], the contribution of specific crystal packing may be expected. In contrast to straight one-dimensional chain structures of $\left[\mathrm{Cu}(N \text {-ethylethyledimamie })_{2}\right]\left[\mathrm{Ni}(\mathrm{CN})_{4}\right]$ and the analogous $\mathrm{d}^{8}$ metal complexes $[9,10]$, bent bond angles associated with the long $\mathrm{Cu}-\mathrm{N}$ bond for $\mathbf{1}$ in a specific crystal packing are quite small resulting in weak interaction and less orbital overlap of typical example of $\pi$-backdonation. Furthermore, 1 and several related coordination polymers exhibited reversible releasing and containing of guest crystalline water molecules by heating and cooling. The crystal structure

*Address correspondence to this author at the Department of Chemistry, Faculty of Science, Tokyo University of Science, 1-3 Kagurazaka, Shinjukuku, Tokyo 162-8601, Japan; Tel: +81-3-5228-8271; Fax; +81-3-5261-4631; E-mail: akitsu@ @rs.kagu.tus.ac.jp determination based on powder XRD data reported by Sereda et al. [11-13] suggested that the resulting reversible structural changes were between zigzag (containing water molecules) and straight (losing water molecules) onedimensional cyanide-bridges of host MOF.

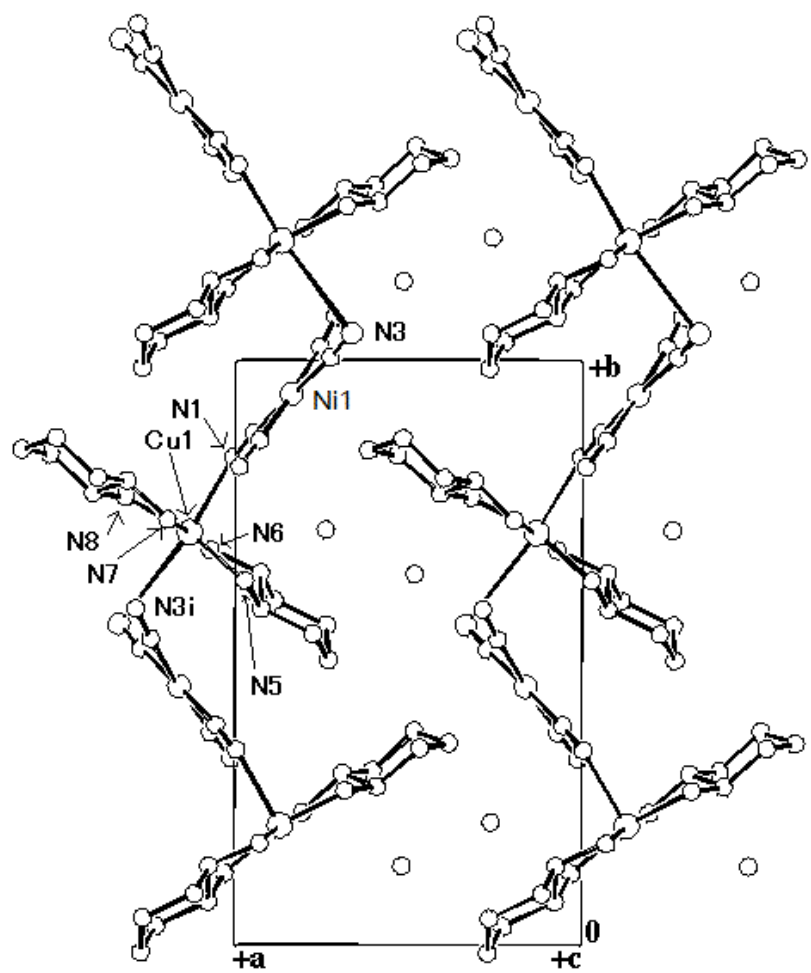

Fig. (1). Crystal structure of $\mathbf{1}$.

Herein, we have investigated thermally accessible structural changes of $\mathbf{1}$ by cooling less than room temperature. We could successfully observe separately NTE for the long $\mathrm{Cu}-\mathrm{N}$ bond and PTE for the rest of $\mathrm{Cu}$ coordination environment and crystal lattice isotropically. Consequently, the characteristic crystal packing to form zigzag onedimensional chain of $\mathbf{1}$ is found to be the predominant reason 
for this long $\mathrm{Cu}-\mathrm{N}$ bond exhibiting interesting temperature dependence.

\section{MATERIALS AND METHODOLOGY}

\section{General Procedure}

Chemicals and solvents of the highest commercial grade available (Kanto Chemical, Tokyo Chemical Industry, and Wako) were used as received without further purification. Preparations of $\mathbf{1}$ was carried out according to the literature [7].

\section{Powder X-ray Diffraction}

Powder XRD patterns were measured by using synchrotron radiation beamline at KEK-PF BL-8B (proposal No. 2008 G526) with $8 \mathrm{keV}(\lambda=1.54184 \AA$ ) under variable temperature apparatus of nitrogen stream (100-300 K) equipped with a RIGAKU imaging plate. All the samples were measured for $3 \mathrm{~min}$ and constant ring current (440 mA).

\section{Single Crystal X-ray Crystallography}

The diffraction data were treated using SMART and SAINT [14], and absorption correction was performed using SADABS [15]. The structure was solved by direct methods using SHELXTL [16]. Non hydrogen atoms were refined anisotropically. All hydrogen atoms that could be found clearly were generated geometrically. Axis setting conversion of monoclinic cell was applied to compare with the previous data.

Crystal structural data of $\mathbf{1}$ at $100 \mathrm{~K}: \mathrm{C}_{16} \mathrm{H}_{28} \mathrm{CuN}_{8} \mathrm{NiO}_{2}$, monoclinic, space group $P 2_{1} ; a=9.7727(18), b=15.263(3)$, $c=7.9197(15) \AA, \beta=109.613(2){ }^{\circ}, V=1114.2(4) \AA^{3}, Z=2$, $M_{\mathrm{r}}=486.70, D_{\mathrm{c}}=1.451 \mathrm{gcm}^{-1}, 6240$ reflections measured, 4407 independent. Final $R_{1}=0.0298,{ }_{\mathrm{w}} R_{2}=0.0880$. Mo-K $\alpha$ radiation $(\lambda=0.71073 \AA)$.

Crystal structural data of $\mathbf{1}$ at $150 \mathrm{~K}: \mathrm{C}_{16} \mathrm{H}_{28} \mathrm{CuN}_{8} \mathrm{NiO}_{2}$, monoclinic, space group $P 2_{1} ; a=9.7883(7), b=15.2927(11)$, $c=7.9461(6) \AA, \beta=109.796(10){ }^{\circ}, V=1119.16(14) \AA^{3}$, $Z=2, M_{\mathrm{r}}=486.70, D_{\mathrm{c}}=1.444 \mathrm{gcm}^{-1}, 6325$ reflections measured, 4456 independent. Final $R_{1}=0.0232,{ }_{\mathrm{w}} R_{2}=0.0660$. Mo-K $\alpha$ radiation $(\lambda=0.71073 \AA)$.

Crystal structural data of 1 at $173 \mathrm{~K}: \mathrm{C}_{16} \mathrm{H}_{28} \mathrm{CuN}_{8} \mathrm{NiO}_{2}$, monoclinic, space group $P 2_{1} ; a=9.8014(9), b=15.3051(14)$, $c=7.9522(7) \AA, \beta=109.85(10)^{\circ}, V=1122.04(18) \AA^{3}, Z=2$, $M_{\mathrm{r}}=486.70, D_{\mathrm{c}}=1.441 \mathrm{gcm}^{-1}, 6366$ reflections measured, 4481 independent. Final $R_{1}=0.0226,{ }_{w} R_{2}=0.0654$. Mo-K $\alpha$ radiation $(\lambda=0.71073 \AA)$.

Crystal structural data of $\mathbf{1}$ at $223 \mathrm{~K}: \mathrm{C}_{16} \mathrm{H}_{28} \mathrm{CuN}_{8} \mathrm{NiO}_{2}$, monoclinic, space group $P 2_{1} ; a=9.8244(7), b=15.3367(11)$, $c=7.9683(6) \AA, \beta=110.014(10)^{\circ}, V=1128.11(14) \AA^{3}, Z=2$, $M_{\mathrm{r}}=486.70, D_{\mathrm{c}}=1.433 \mathrm{gcm}^{-1}, 6420$ reflections measured, 4459 independent. Final $R_{1}=0.0237,{ }_{\mathrm{w}} R_{2}=0.0687$. Mo-K $\alpha$ radiation $(\lambda=0.71073 \AA)$.

Crystal structural data of $\mathbf{1}$ at $296 \mathrm{~K}: \mathrm{C}_{16} \mathrm{H}_{28} \mathrm{CuN}_{8} \mathrm{NiO}_{2}$, monoclinic, space group $P 2_{1} ; a=9.851(4), b=15.359(6)$, $c=7.991(3) \AA, \beta=110.261(5)^{\circ}, V=1134.2(8) \AA^{3}, Z=2$, $M_{\mathrm{r}}=486.70, D_{\mathrm{c}}=1.437 \mathrm{gcm}^{-1}, 6482$ reflections measured, 4377 independent. Final $R_{1}=0.0326,{ }_{w} R_{2}=0.0917$. Mo-K $\alpha$ radiation $(\lambda=0.71073 \AA)$.

\section{RESULTS AND DISCUSSION}

Fig. (2) depicts temperature dependence (300-100 K) of powder XRD patterns of $\mathbf{1}$ measured with synchrotron radiation. Detailed examination of peaks about shifts, intensity and width indicated isotropic PTE of lattice strain.

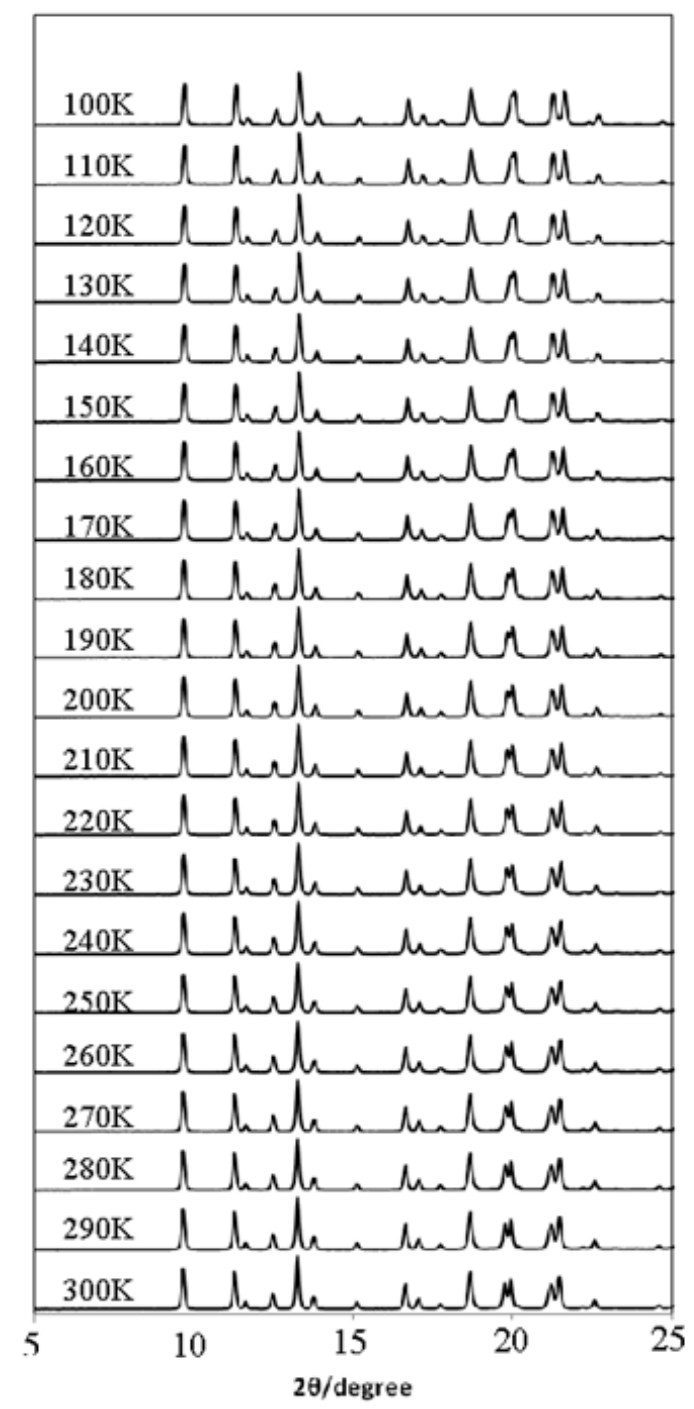

Fig. (2). Temperature dependence of XRD patterns of $\mathbf{1}$.

If there was obvious anisotropy of crystal packing, some XRD peaks associated with might indicate irregular shifts. Recently we have reported that disagreement of direction of peak shifts by means of variable temperature powder XRD measurement [17]. For this case of a certain cyanide-bridged $\mathrm{Cu}-\mathrm{Ag}$ complex, thermally induced anisotropic lattice strain was caused by structural flexibility between weak $\mathrm{d}^{10}-\mathrm{d}^{10}$ metallophillic interactions and relative rigidity associated with cyanide-bridges of the $\left[\mathrm{Ag}(\mathrm{CN})_{2}\right]^{-}$moiety and JahnTeller distortion of a $\mathrm{Cu}-\mathrm{N}$ bond.

Single crystal structural determination of $\mathbf{1}$ measured with an X-ray generated by $\mathrm{MoK} \alpha$ radiation also supports the temperature dependence of crystal lattice parameters, $a$, $b, c, \beta$, and $V$ in $P 2_{1}$ space group. Table 1 lists temperature dependence of six $\mathrm{Cu}-\mathrm{N}$ bond distances of 1 around $\mathrm{Cu}$ coordination environment, in which Cu1-N5, Cu1-N6, Cu1-N7, 
Table 1. Temperature Dependence of Cu-N Bond Distances and Tetragonality $(T)$ of 1

\begin{tabular}{|c|c|c|c|c|c|}
\hline Cu1-N1/ & $2.302(2)$ & $2.303(2)$ & $2.307(2)$ & $2.316(2)$ & $2.321(3)$ \\
\hline Cu1-N5/ & $2.019(2)$ & $2.0185(17)$ & $2.0161(17)$ & $2.018(19)$ & $2.013(2)$ \\
\hline Cu1-N6/ & $2.006(2)$ & $2.013(2)$ & $2.013(2)$ & $2.010(2)$ & $2.013(3)$ \\
\hline Cu1-N8/ & $2.038(2)$ & $2.031(16)$ & $2.0295(16)$ & $2.0306(18)$ & $2.024(2)$ \\
\hline$T$ of N1 & 0.878584 & 0.877931 & 0.875878 & 0.872366 & 0.869453 \\
\hline$T$ of $\mathrm{N} 3$ & 0.643903 & 0.645142 & 0.644135 & 0.645289 & 0.648249 \\
\hline
\end{tabular}

and $\mathrm{Cu} 1-\mathrm{N} 8$ are in-plane bonds linked by $\mathrm{NH}_{2}$ groups. Whereas $\mathrm{Cu} 1-\mathrm{N} 1$ and $\mathrm{Cu} 1-\mathrm{N} 3^{\mathrm{i}}$ bonds are long (within a normal range for $\mathrm{Cu}-\mathrm{N}$ bond distances of Jahn-Teller elongation) and characteristic long axial bonds linked by $\mathrm{NC}$ groups. The $T$ values denote tetragonality of distorted octahedral $\mathrm{Cu}$ coordination geometry whose definition is $T=$ in-plane $\mathrm{Cu}-\mathrm{N}$ bond distances / axial $\mathrm{Cu}-\mathrm{N}$ bond distances $[18,19]$.

As emphasized in Fig. (3), only the axial $\mathrm{Cu} 1-\mathrm{N} 3^{\mathrm{i}}$ bond distances is elongated on cooling (NTE), though the rest of coordination bonds, namely the axial $\mathrm{Cu} 1-\mathrm{N} 1$ bond and the in-plane $\mathrm{Cu} 1-\mathrm{N} 4$ through $\mathrm{N} 6$ bonds are elongated by heating (PTE). The magnitude of differences of bond distances is not within e.s.d.'s and displacement parameters of $\mathrm{Cu} 1$ and N1 and N3 through N6 atoms exhibit normal temperature dependence.

The reason for this novel behavior is mainly attributed to appropriate crystal packing structure of 1. Most interesting structural feature is emerged as $\mathrm{Cu}-\mathrm{N}$ bond distances. However, specific reasons for lattice strain could not be found as specific interatomic distances (probably void space may be concerned). Contrary to heating behavior [11-13], releasing crystalline water accompanying by drastic structural change is not responsible for this cooling behavior. Additionally, we could not add hydrogen atoms of crystalline water molecules and we could not discuss detailed features of hydrogen bonds. However, positions of most non-hydrogen atoms were kept after changing temperature. The arrangement of rigid coordination polyhedron is kept in this temperature range not to reduce void space in the crystals. Structural or magnetic phase transition did not occur for $\mathbf{1}$ in this temperature range [7]. Some NTE materials have anisotropy of lattice vibration, contracted axis is perpendicular to the elongated axis for this case. For the case of 1 , the $\mathrm{Cu} 1-\mathrm{N} 3{ }^{\mathrm{i}}$ bonds are approximately along the bisectrix of the $b$ and $c$ axes or the $\mathrm{b}$ and $\mathrm{a}$ axes. However, $\mathrm{Cu} 1-\mathrm{N} 1$ bonds offset the flexibility of $\mathrm{Cu} 1-\mathrm{N} 3^{\mathrm{i}}$ bonds in view of vibration of bonds.

Indeed, theoretical discussion suggests the possibility of both elongated and shorten Jahn-Teller distortion (so-called Jahn-Teller switching) to reduce degeneracy orbitals occupying unpaired electrons of $\mathrm{d}^{9} \mathrm{Cu}(\mathrm{II})$ ions by coupling appropriate normal modes $[20,21]$. Similar consideration may be valid for pseudo Jahn-Teller distortion systems of lower symmetry than exact $O_{h}$ symmetry containing different ligands. However, to our knowledge based on a series of investigation about the related compounds showing JahnTeller distortion $[18,19]$, we have never observed thermally accessible structural change opposite tendency against temperature dependence. In this way, both Jahn-Teller contraction in a crystal lattice and elongation on cooling (NTE be-
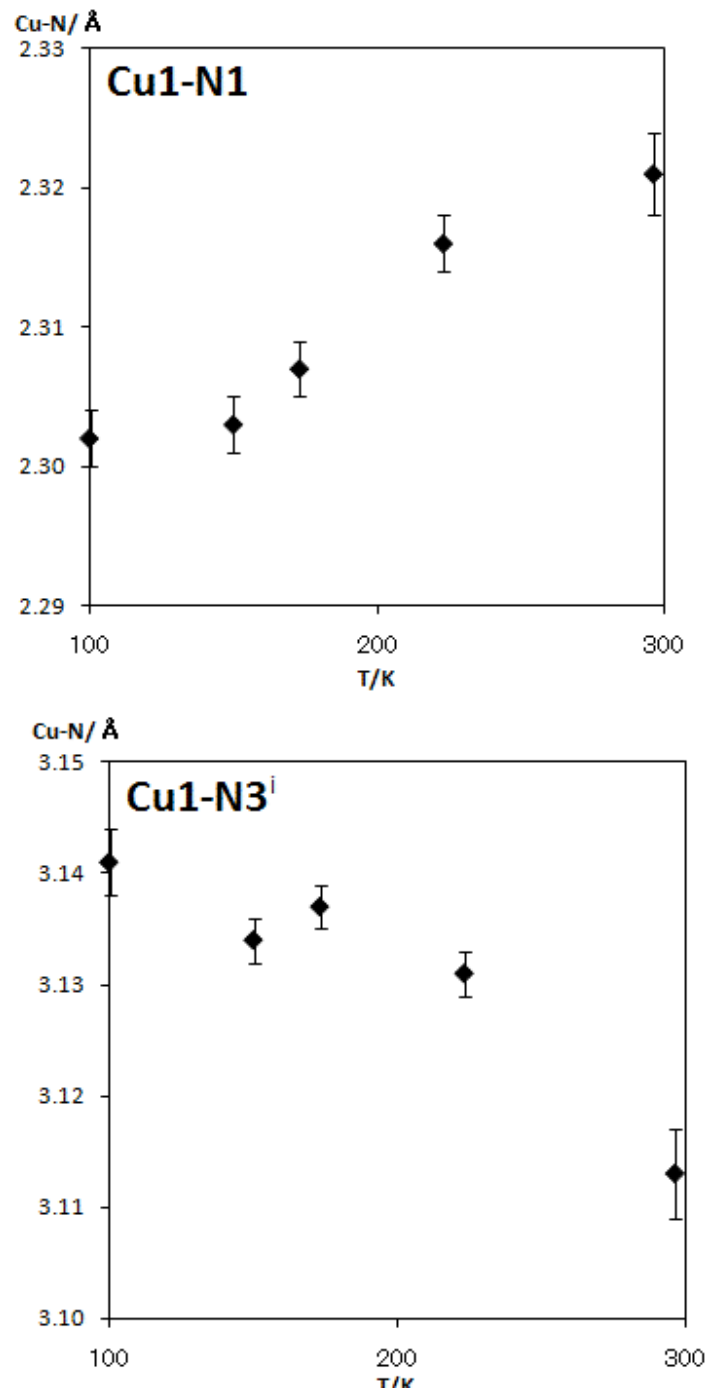

Fig. (3). Temperature dependence of short axial $\mathrm{Cu} 1-\mathrm{N} 1$ and long axial $\mathrm{Cu} 1-\mathrm{N} 3^{\mathrm{i}}$ bond distances of 1 . Error bars denotes 1 e.s.d. ranges. 
havior about a specific Jahn-Teller distorted bond) may be difficult to find for actual crystalline materials.

\section{CONCLUSION}

In summary, we have discovered a novel temperature dependence of a Jahn-Teller distorted bond for a cyanidebridged $\mathrm{Cu}-\mathrm{Ni}$ coordination polymer of zigzag onedimensional crystal packing by chance.

\section{SUPPLEMENTARY DATA}

CCDC (779350-779354) contains the supplementary crystallographic data. These data can be obtained free of charge via http://www.ccdc.cam.ac.uk/conts/retrieving.html, or from the Cambridge Crystallographic Data Centre, 12 Union Road, Cambridge CB2 1EZ, UK; fax: (+44) 1223336-033; or e-mail: deposit@ccdc.cam.ac.uk.

\section{ACKNOWLEDGEMENTS}

We are gratefully acknowledged to KEK-PF BL-8B (2008G526) for X-ray crystallography using synchrotron radiation.

\section{REFERENCES}

[1] Evans JSO. Negative thermal expansion materials. J Chem Soc Dalton Trans 1999; 3317-26.

[2] Goodwin AL, Chapman KW, Kepert CJ. Guest-dependent negative thermal expansion in nanoporous prussian blue analogues $\mathrm{M}^{\mathrm{II}} \mathrm{P}$ $\mathrm{t}^{\mathrm{IV}}(\mathrm{CN})_{6} \cdot \mathrm{x}\left\{\mathrm{H}_{2} \mathrm{O}\right\}(0 \leq \mathrm{x} \leq 2 ; \mathrm{M}=\mathrm{Zn}, \mathrm{Cd})$. J Am Chem Soc 2005; 127: $17980-1$.

[3] Goodwin AL, Kennedy BJ, Kepert CJ. Thermal expansion matching via framework flexibility in zinc dicyanomellates. J Am Chem Soc 2009; 131: 6334.

[4] Goodwin AL, Calleja M, Conterio MJ, et al. Colossal positive and negative thermal expansion in the framework material $\mathrm{Ag}_{3}\left[\mathrm{Co}(\mathrm{CN})_{6}\right]$. Science 2008; 319: 794-7.

[5] Korcok JL, Katz MJ, Leznoff DB. Impact of metallophilicity on "colossal" positive and negative thermal expansion in a series of isostructural dicyanometallate coordination polymers. J Am Chem Soc 2009; 131: 4866-71.

[6] Das D, Jacobs T, Barbour L J. Exceptionally large positive and negative anisotropic thermal expansion of an organic crystalline material. Nat Mater 2010; 9: 36-9.
[7] Akitsu T, Einaga Y. Extremely long axial cu-n bonds in chiral onedimensional zigzag cyanide-bridged $\mathrm{Cu}^{\mathrm{II}}-\mathrm{Ni}^{\mathrm{II}}$ and $\mathrm{Cu}^{\mathrm{II}}-\mathrm{Pt}^{\mathrm{II}}$ bimetallic assemblies. Inorg Chem 2006; 45: 9826-33.

[8] Akitsu T, Einaga Y. Tuning of electronic properties of onedimensional cyano-bridged $\mathrm{Cu}^{\mathrm{II}}-\mathrm{Ni}^{\mathrm{II}}, \mathrm{Cu}^{\mathrm{II}}-\mathrm{Pd}^{\mathrm{II}}$, and $\mathrm{Cu}^{\mathrm{II}}-\mathrm{Pt}^{\mathrm{II}}$ bimetallic assemblies by stereochemistry of ligands. Inorg Chim Acta 2008; 361: 36-42.

[9] Akitsu T, Einaga Y. Structures, magnetic properties, and XPS of one-dimensional cyanide-bridged $\mathrm{Cu}^{\mathrm{II}}-\mathrm{Ni}^{\mathrm{II}} / \mathrm{Pt}^{\mathrm{II}}$ bimetallic assembly complexes. Inorg Chim Acta 2007; 360: 497-505.

[10] Akitsu T, Endo Y. The one-dimensional chain structure of $\mathrm{Cu}(\mathrm{N}$ Eten $)_{2} \mathrm{Pd}(\mathrm{CN})_{4}(\mathrm{~N}-$ Eten $=\mathrm{N}$-ethylethylenediamine $)$. Acta Cryst E 2009; 65: m406-7.

[11] Sereda O, Stoeckli-Evans H, Dolomanov O, Filinchuk Y, Pattison P. Transformation of a chiral nanoporus bimitallic cyano-bridged framework triggered by dehydration/rehydration. Crystal Growth Des 2009; 9: 3168-78.

[12] Sereda O, Neels A, Stoeckli F, Stoeckli-Evans H, Filinchuk Y. Sponge-like reversible transformation of a bimetallic cyanometallate polymer. Crystal Growth Des 2008; 8: 2307-11.

[13] Sereda O, Neels A, Stoeckli F, Stoeckli-Evans H. Chiral bimetallic assemblies and coordination polymers based on tetracyanonickelate: a striking reversible structural transformation. Crystal Growth Des 2008; 8: 3380-4.

[14] Bruker. SMART and SAINT. Bruker AXS Inc., Madison, Wisconsin, USA, 1998.

[15] Sheldrick GM. SADABS. Program for empirical absorption correction of area detector data, University of Gottingen, Germany, 1996.

[16] Sheldrick GM. A Short History of SHELX. Acta Crystallogr. A 2008; 64: 112-9.

[17] Akitsu T, Sano K. Analogy of van't Hoff relationship for thermallyaccessible lattice strain of copper(II) complex. Netsu Sokutei 2009; 36: $244-6$.

[18] Akitsu T, Einaga Y. Thermal and photo-responsibiliry of axial semi-coordination bonds in copper(ii) complex. Bull Chem Soc Jpn 2004; 77: 763-4.

[19] Akitsu T, Einaga Y, Yoza K. Thermally-accessible lattice strain and local pseudo jahn-teller distortion in various dimensional $\mathrm{Cu}^{\mathrm{II}}$ $\mathrm{M}^{\mathrm{III}}$ bimetallic cyanide-bridged assemblies. Open Inorg Chem $\mathrm{J}$ 2008; 2: 1-10.

[20] Falvello LR, Jahn-Teller effects in solid-state co-ordination chemistry. J Chem Soc Dalton Trans 1997; 4463-75.

[21] Halcrow MA. Interpreting and controlling the structures of sixcoordinate copper(II) centres - When is a compression really a compression? Dalton Trans 2003; 4375-84. 